\title{
Comunicação e saúde: humanização, significado e ação comunicativa
}

Communication and health: humanization, meaning and communicative action

Comunicación y salud: humanización, significado y acción comunicativa

\section{Denise Werneck Carvalho}

- Doutora em Ciências da Saúde e mestre em Informática pela Pontifícia Universidade Católicado Paraná (PUC-PR)

- Professora titular do curso de Comunicação Social da PUC-PR

- Avaliadora ad hoc do Instituto Nacional de Estudos e Pesquisas Educacionais (Inep)

- Consultora na área de comunicação empresarial e saúde

- E-mail: denisewerneck.f@gmailcom

\section{Maria Teresa Marins Freire}

- Doutora em Ciências da Saúde e mestre em Educação pela Pontificia Universidade Católica do Paraná (PUC-PR)

- Graduada em Jornalismo pela Universidade Federal do Paraná (UFPR) e em Langue et Civilisation Françaises pela Université de Nancy (França)

- Professora titular do curso de Comunicação Social da PUC-PR

- Consultora na área de jornalismo comunitário, cultural, empresarial e de saúde

- E-mail: freire.mteresa@gmail.com

\section{Guilherme Vilar}

- Doutor em Génie Biomédicale pela Université de Technologie de Compiègne (França)

- Mestre em Engenharia Biomédica pela Universidade Federal da Paraíba (UFPB) Graduado em Engenharia Elétrica pela UFPB.

- Professor adjunto da Universidade Federal Rural de Pernambuco (UFRPE)

- Consultor nas áreas de telemedicina, informática médica e comunicação em saúde

- E-mail: guilherme_vilar@yahoo.com.br 


\section{Resumo}

O objetivo deste artigo é analisar o binômio comunicação-saúde sob a perspectiva do agir comunicativo de Jürgen Habermas. Em um país com cerca de 191 milhões de habitantes, a comunicação deve subsidiar as políticas públicas de promoção da saúde, para tornar democráticas as práticas gerenciais e sanitárias. A humanização dos serviços e a atuação das equipes multiprofissionais exigem interação e acordo entre os sujeitos. O agir comunicativo pode trazer esse significado, com sustentação do diálogo e da cooperação, apontando nova direção baseada nos acordos sociais para produção dos serviços de saúde.

PALAVRAS-CHAVE: UNIDADE DE SAÚDE • POLÍTICAS DE SAÚDE • AGIR COMUNICATIVO • RELAÇÕES HUMANIZADAS • FORÇA EDUCATIVA

\section{Abstract}

This article aims at analyzing the relation between communication and health under the communicative action perspective of Jürgen Habermas. In a country with almost 191 million inhabitants communication must support the health promotion public policies in order to organize democratically the management and sanitary practices. The humanization of the services and the work of the multi-professional teams demand integration and agreement among the subjects. Habermas' communicative action can offer this meaning, thereby sustaining dialogue and cooperation, pointing in a new direction based on the social agreements for production of health services.

KEYWORDS: HEALTH UNITY • HEALTH POLICIES • COMMUNICATIVE ACTION • HUMANIZED RELATIONSHIP • EDUCATIONAL FORCE

\section{Resumen}

El objetivo de este artículo es analizar el binomio comunicación-salud a partir de la perspectiva de la acción comunicativa de Jürgen Habermas. En un país con cerca de 191 millones de habitantes, la comunicación debe subsidiar las políticas públicas de promoción de la salud, para volver democráticas las prácticas gerenciales y sanitarias. La humanización de los servicios y la actuación de los equipos multiprofesionales exigen interacción y alianzas entre los sujetos. El actuar comunicativo puede traer ese significado, con la sustentación del diálogo y la cooperación, señalando una nueva dirección basada en los acuerdos sociales para la producción de los servicios de salud.

PALAVRAS-CHAVE: UNIDAD DE SALUD • POLÍTICAS DE SALUD • ACTUACIÓN COMUNICATIVA• RELACIONES HUMANIZADAS • FUERZA EDUCATIVA 
M arcado por extremas desigualdades sociais e extensa territorialidade, o Brasil é um país de profundos contrastes. O modelo hospitalocêntrico caracterizado pela inviabilidade em vários países também não satisfaz um país com a dimensão do Brasil e cerca de 191milhões de habitantes.

O desafio de atingir a meta de "saúde para todos", proposta pela Organização Mundial de Saúde (OMS), na Conferência Internacional sobre Cuidados Primários de Saúde (1978), coloca o governo na berlinda ao forçá-lo a não apenas criar e manter políticas de desenvolvimento para a saúde, mas também a assegurar práticas que as sustentem.

Práticas gerenciais e sanitárias, democráticas e participativas, buscam promover a integralidade dos serviços de saúde em seus vários aspectos, a saber: integração de ações programáticas e demanda espontânea; articulação das ações de promoção da saúde, prevenção de agravos, vigilância da saúde, tratamento e reabilitação; trabalho de forma interdisciplinar e em equipe; e coordenação do cuidado na rede de serviços.

No Brasil, a Estratégia de Saúde da Família (ESF) se constitui na principal estratégia de reorientação do modelo assistencial, mediante implantação de equipes multiprofissionais em unidades básicas de saúde. As equipes são responsáveis pelo acompanhamento de um número definido de famílias, localizadas em áreas geográficas delimitadas, e atuam em ações de promoção da saúde, prevenção, recuperação e reabilitação de doenças e agravos, bem coo na manutenção da saúde dessa comunidade (Brasil, 2006).

Os profissionais devem realizar bem o seu trabalho e conhecer o trabalho dos demais, em atitude de cooperação, para continuar aprendendo em seu ambiente. A fim de aprender com e sobre os outros, é importante que conheçam, entendam e aceitem os princípios que norteiam o trabalho.

Oferecer qualidade em saúde nessas proporções é tarefa complexa e penosa, se consideramos que a estrutura do SUS (Serviço Único de Saúde) não dá conta de um quadro de doenças de todos os tipos, condicionadas e agravadas pelas alarmantes diferenças sociais e econômicas das regiões e as quais não se consegue diminuir. Do outro lado, e por consequência, a desintegração das unidades de saúde implica sobreoferta de serviços em alguns locais, enquanto outros permanecem em total desassistência.

Na mesma direção, na atualidade, a saúde tem sido questionada quanto aos seus princípios éticos e da relação profissional-paciente. No modelo hospitalocêntrico, universalizante e criado pelo sistema estatal, o conceito de saúde é um direito inalienável do ser humano e que deve ser garantido pelo Estado. O governo assumiu a responsabilidade pelos serviços de saúde considerados de caráter público, quer na prevenção ou com fins de cura. Com o decorrer do tempo, no entanto, o modelo acumulou muitos problemas por se centrar na figura do médico e do hospital, elevando extraordinariamente os custos de assistência à saúde e valorizando sobremaneira 
a especialização médica, os equipamentos, as máquinas e os fármacos, além de promover o desenvolvimento tecnológico em detrimento das necessidades dos usuários/pacientes (Franco; Merhy, 2003, p. 13).

A lógica do modelo hospitalocêntrico passou a ser a mesma lógica capitalista do campo econômico em geral - a obtenção e o acúmulo do capital; isto é, a produção de serviços é estruturada e comandada por interesses dessa ordem.

Essa situação reflete, então, uma cobertura assistencial excludente, imposta principalmente aos segmentos populacionais de baixa renda e de regiões mais carentes, que não chegam a receber condições mínimas de atendimento.

O conflito entre os setores público e privado, disputando conveniados e contratados, se constitui em outro nó, fragmentando o processo decisório, ao torná-lo moroso, burocrático e pouco funcional. Os problemas não param por aí, sendo que a proposta de um serviço integral para a família esbarra, também, na baixa qualidade de equipamentos e serviços profissionais.

Por certo, uma política efetiva de educação continuada pode dar conta do desenvolvimento essencial que as equipes devem ter para prestar um serviço de qualidade, considerando a rotina de pressões e de poucos recursos dos profissionais.

\section{AÇÃO COMUNICATIVA E SAÚDE}

Nessa perspectiva, a teoria da ação comunicativa de Habermas pode ser aplicada no contexto das políticas de saúde ao tratar de um acordo entre os sujeitos, com base na interação. O pensamento habermasiano é proposto como alicerce e orientação de uma ação multiprofissional que tenha como base a interação dos indivíduos envolvidos para a solução de um problema em saúde e para produção de conhecimento em comunicar para a saúde. Isso, tendo em vista que, para Habermas, a racionalidade é tida como inspiradora das relações em sociedade e permite a autonomia dos indivíduos, possibilitando maior entendimento do mundo.

A adesão dos profissionais de saúde aos princípios que norteiam o objetivo do trabalho a ser realizado necessita estar consolidada, quer pelo aspecto social, de desempenho ou do ponto de vista dos objetivos do governo - que estabelece as diretrizes. Um bom resultado dependerá da adesão individual dos profissionais, além da necessidade de entenderem-se mutuamente, a partir de acordos previamente efetuados. 
Por outro lado, a saúde deve ser vista como um direito social que contempla todas as pessoas. Deve, também, ser entendida no seu conceito mais amplo, suficiente para que o indivíduo se desenvolva em todos os aspectos da sua vida - social, econômica, cidadã (adaptação ao meio e respeito a ele), mostrando-se capaz de compreender, analisar e interagir com a própria realidade e o mundo, para transformá-los. Nessa situação, a saúde torna-se um bem de todos, sendo mais do que um estado de bem-estar, mas determinada por um modo de ação em que todos estão comprometidos com o bem-estar, a produção e os cuidados.

Aqui, importa apresentar a ação comunicativa como um valioso recurso para a área da saúde, no que se refere tanto à produção do conhecimento, quanto às práticas que envolvem profissionais, pacientes e governo. Os aspectos socioantropológicos da comunicação não apenas possibilitam examinar e discutir teórica e empiricamente a condição humana frente às transformações da sociedade contemporânea. Também permitem promover o desenvolvimento dos indivíduos a partir de elementos como a interação, a informação e a formação de hábitos e atitudes, apenas para citar alguns exemplos.

Assim, formulam-se duas perguntas. A comunicação pode modificar comportamentos e ações? E é possível capacitar pessoas tomando-se por base o conceito da ação comunicativa?

Promover mudanças na área da saúde exige a proposição de planos de ações em diferentes esferas. É preciso, por exemplo, estratégias propostas especificamente para cada área, situação, público ou cenário, considerando que técnicas não constituem fins em si mesmas, mas meios ordenados e seguros para operar mudanças. Dessa forma, entendida como área essencial para suporte a outros campos de conhecimento, a comunicação favorece a criação de recursos metodológicos para transformação da realidade. Não se trata apenas de promover ações, mas de justificá-las face às condições reais em que os objetivos são propostos e os recursos disponibilizados.

\section{Atributos da comunicação em favor da saúde}

Nessa perspectiva, a execução das atividades deve privilegiar elementos identificados para solução do problema apresentado. Como instrumento de ação política, a comunicação é facilitadora da gestão da saúde, favorecendo a mediação de interesses e identificando necessidades de diferentes naturezas. Também é indicada para promover e educar para a saúde, sugerir e recomendar mudanças de comportamento, informar sobre a saúde e sobre as doenças, sobre quais e quando devem ser realizados exames médicos, recomendar medidas preventivas e atividades de autocuidados aos pacientes e educar os usuários sobre assuntos de saúde, a fim de melhorar a acessibilidade dos serviços. No que se refere aos profissionais de saúde, pode melhorar significativamente as relações interprofissionais, a comunicação interna dos hospitais e das unidades e a qualidade dos serviços. 
Por isso, a comunicação é trazida como recurso para compreensão do objeto e intervenção nas questões de saúde. Como domínio de conhecimento, a comunicação pode ser vista como área meio, à medida que possibilita espaço para debate e análise crítica de assuntos relacionados a outras ciências. Como metodologia, fornece o ambiente propício ao diálogo e favorece o confronto de ideias. No entanto, popularmente, a comunicação é vista e entendida especialmente na relação que se estabelece entre emissor e receptor, sendo que, como fenômeno, essa relação é apenas parte de um extenso sistema que inclui vários outros elementos (Wolf, 1995, p. 271).

\section{Competência em comunicação de saúde}

No campo da saúde, a comunicação exerce uma força educativa pela qual vem sendo cada vez mais observada. O fenômeno da educação em saúde se apresenta como um jogo de vários saberes, que "constituem as práticas e as reflexões envolvidas nas relações entre educação e comunicação na área da saúde" (Donato; Gomes, 2010, p. 42). Assim, alguns questionamentos cabem na proposição de uma política de saúde capaz de formar equipes mais atuantes e envolvidas com os objetivos do SUS. Como deve ser um profissional de saúde para as Unidades Básicas de Saúde (UBS)? O que se espera dele? Quais competências comunicacionais ele deve reunir? Como deve ser sua relação com a equipe? Como elevar o nível de adesão aos princípios estabelecidos pelo governo?

É importante ressaltar que os profissionais fazem parte da rotina de muitos pacientes, exercendo um papel fundamental na vida das pessoas. Significa que devem possuir este entendimento e que devem se posicionar claramente acerca de suas tarefas e competências no exercício de suas funções. Devem se perguntar o que fazer, como fazer e quando fazer, distinguir momentos quase imperceptíveis nos quais devem falar ou calar-se, identificar possíveis fontes de conflito ou estresse e observar diferentes necessidades de atendimento, conforme o estado emocional do paciente ou conforme a patologia exigir.

Com o principal propósito de reorganizar a prática da atenção à saúde em substituição ao modelo tradicional (que valorizava o hospital), se espera das UBS um atendimento de qualidade, atuando na prevenção de doenças e diminuindo o número de internações de forma a levar a saúde para mais perto da comunidade.

No entanto, algumas complexidades se associam a esse propósito, ao se considerarem os aspectos humanos, logísticos e de prestação de serviços nas diferentes localidades em que as UBS se localizam. Do ponto de vista das equipes que prestam atendimento, o Ministério da Saúde (MS) relaciona uma longa lista de competências que os profissionais devem reunir, das quais fazem parte não apenas o conjunto de tarefas que lhes cabem, mas também aspectos relacionados a formas de conscientização, de formação da opinião e de incorporação de hábitos, comportamentos e atitudes. 
Por exemplo, faz parte do conjunto de competências dos profissionais que integram as UBS conhecer a realidade das famílias que atendem, no que se refere aos aspectos sociais, econômicos, culturais, demográficos e epidemiológicos. Tal capacidade exige não apenas discernir fatores demográficos e fisiográficos, mas, também, analisar as condições que resultam da realidade desses quadros. Outra competência que se relaciona não apenas a um fator técnico, mas a uma capacidade a ser construída, é a valorização da relação com o usuário e sua família, para criação de vínculo de confiança, afeto e respeito.

O desenvolvimento profissional, na ótica da comunicação, atende à necessidade permanente de definição, identificação, mapeamento e utilização de novas competências. Sobre isso comenta Denise M. de Carvalho (2003, p. 16):

O conceito de competência nos diz ser ela fator primordial para a conduta humana quando da realização de procedimentos ou tarefas. Não apenas pelo fato do realizar coisas corretamente e de forma válida, mas por conferir ao homem o sentido humano de suas capacidades. Ser competente significa, de modo amplo, estar no mundo de forma útil e participativa. Dessa forma, no que fazem e no modo como realizam coisas, as pessoas precisam se sentir integradas ao mundo, sendo isso o que as capacita a interagir sobre ele.

Ao referir que "a competência expressa uma necessidade social de fórum íntimo, fazendo parte da integralização do indivíduo" (Carvalho, 2003, p. 17), a autora acentua que desenvolver competências faz parte do ser social do indivíduo, sendo fundamental o estímulo a novos saberes. Na particularidade de trabalhos cujo desempenho exija a atuação de vários profissionais, essa condição se faz ainda mais presente ao considerar que, primeiro, para atingir bons resultados, cada profissional de uma equipe deve exercer bem seu trabalho; segundo, é necessário que o grupo reconheça o trabalho de cada um de seus membros e o valorize como parte do trabalho de todos, o que se traduz na integração para realização da tarefa.

Outro aspecto importante diz respeito à significação ampla e rica de uma competência, que, mais frequentemente, se tem associado ao fato de realizar uma coisa bem ou corretamente e de forma válida. De fato, trata-se de uma qualidade requerida, mas que se refere apenas ao produto final (o ato), desconsiderando que

a competência traz, em sua base, a singularidade do indivíduo. Por isso, embora duas pessoas possam realizar a mesma tarefa de forma correta, o modo de cada uma realizá-la dará medidas diferentes para o reconhecimento de cada uma delas. Este modo particular resulta do subconjunto de atributos que incidem no modo de fazer as coisas e, por isso mesmo, se relaciona mais intimamente à natureza de cada um. Essa elasticidade dificulta, então, nominar ou qualificar o jeito de se fazer coisas. Em dada situação, isto pode ser visualizado através de um rol de procedimentos elencados previamente atendendo critérios de ordem, classificação ou outros, mas a atitude pessoal torna difuso perceber fatores subjacentes (Carvalho, 2003, p. 17). 
Nesse caminho, o processo de identificar, construir e disponibilizar competências de determinado profissional não se relaciona apenas a aperfeiçoar uma técnica ou procedimento, mas, antes, à articulação de diversos elementos para obter o máximo de uma capacidade. A área da saúde exige muito dos profissionais que precisam lidar com as enfermidades do paciente, com as limitações do sistema político de saúde, com as condições socioeconômicas e também com as condições de aprendizagem e trabalho. Esse assunto tem sido alvo de estudo por parte de alguns autores, como Regina R. Witt e Maria C. Almeida (2003) e Ricardo R. Teixeira (2005), que consideram fundamental a noção de competência humana na área da saúde, à medida em que a nova visão de qualidade em saúde considera não só aspectos técnico-instrumentais envolvidos na prática profissional, mas inclui a humanização do cuidado na perspectiva do cliente.

Dessa forma, a competência pode ser vista como uma condição dinâmica que necessita de direcionamento e exercício constante, fazendo parte da formação profissional e geral do indivíduo, sendo que a capacitação profissional possibilita a continuidade do processo de aperfeiçoamento.

O planejamento de uma UBS é realizado com base em áreas de trabalho determinadas, mas para garantir o equilíbrio é preciso que os integrantes interajam de forma sistêmica, relativizando as competências a fim de garantir a unidade multiprofissional, como diz Paulo Freire (2002, p. 69): "A educação é comunicação, é diálogo, na medida em que não é a transferência de saber, mas um encontro de sujeitos interlocutores que buscam a significação dos significados".

No meio da saúde, com jornadas que podem levar à exaustão, e vendo todos os tipos de casos - às vezes experimentando euforia e/ou frustração -, os profissionais são orientados para uma prática que, com frequência, os leva a ver o ser humano dissociado de sua condição social, como se isso fosse possível, seja qual for a condição social do infivíduo.

\section{A LENTE DE HABERMAS}

A abordagem deste artigo se pauta pela ação comunicativa de Jürgen Habermas, filósofo e sociólogo alemão, considerado autor da segunda geração da Escola de Frankfurt.

Aqui, o pensamento habermasiano é proposto como alicerce e orientação de uma ação multiprofissional que tenha como base a interação dos indivíduos envolvidos, para a solução de um problema em saúde, e para produção de conhecimento em saúde, tendo em vista que, para Habermas, a racionalidade é tida como inspiradora das relações em sociedade e permite a autonomia dos indivíduos possibilitando maior entendimento do mundo (Habermas, 1987a, 1987b, 1987c, 1987d).

Ao propor a teoria da ação comunicativa, Habermans parte do princípio de que os homens são capazes de ação, utilizando a linguagem para se comunicar com os seus pares, a fim de chegar 
a um entendimento (larozinski, 2000, p. 13). Também entende que a comunicação pode não apenas reconstruir racionalmente os fundamentos da vida social, mas também superar a visão negativa de desenvolvimento da teoria da sociedade (Rüdiger, 2011; Aragão 1992; Boladeras, 1996; Velasco Arroyo, 2003).

\section{A ação comunicativa}

Habermas (1987b, p. 418) define a ação comunicativa como

aquela forma de interação social em que os planos de ação dos diversos atores ficam coordenados pelo intercâmbio de atos comunicativos, fazendo, para isso, uma utilização da linguagem (ou das correspondes manifestações extraverbais) orientada ao entendimento. À medida que a comunicação serve ao entendimento (e não só ao exercício das influências recíprocas), pode adotar para as interações o papel de um mecanismo de coordenação da ação e com isso fazer possível a ação comunicativa.

Francisco Rüdiger (2011, p. 97) explica que a sociedade não se rege apenas pela razão instrumental. Presa aos esquemas da subjetividade, baseia-se também em uma razão comunicativa, de natureza intersubjetiva, que se constitui no curso da interação social entre os homens. Explica o autor que "a descoberta da razão dialógica permite, portanto, reformular positivamente o diagnóstico pessimista sobre a dialética da razão (subjetiva), reabilitando o projeto de realização humana concebido pela modernidade" (Rudiger, 2011, p. 101).

Assim, a razão instrumental é repensada em termos da razão comunicacional, por meio de relações intersubjetivas, quando dois ou mais sujeitos buscam a interação, visando compreender algum objeto ou assunto, por meio de um posicionamento comum.

As relações intersubjetivas é que permitem identificar a pluralidade dos interesses em uma discussão, sendo neste ponto que se observa a necessidade de reconstruir um espaço crítico e aberto de uma ética da discussão. Habermas (1987b, p. 390) entende a racionalidade como uma fonte inspiradora das ações humanas e que permite a libertação dos homens e maior entendimento do mundo:

Eu mostrarei que uma mudança de paradigma para o da teoria da comunicação tornará possível um retorno à tarefa que foi interrompida com a crítica da razão instrumental. Esta mudança de paradigma nos permite retomar as tarefas, desde então negligenciadas, de uma teoria crítica da sociedade.

Para a Escola de Frankfurt, a racionalidade científica era neutra em relação a valores, e isto bloqueou o exame da razão, tornando subjetivas e irracionais as questões sociais que não se expli- 
cavam pela relação meio-fim. Para seus representantes, a intenção da ciência e da técnica era mesmo a dominação, porque sempre buscavam submeter a natureza ao domínio do homem. Por trás deste entendimento, vê-se uma forma de dominação política no processo de sua construção.

O pensamento de Habermas aceita a racionalidade instrumental da ciência e da técnica porque estas cumprem um sentido de autodefesa do homem. O autor vê no trabalho, por exemplo, a busca pelos meios para atingir determinados fins e, na ciência e na técnica, funções que ampliam as possibilidades humanas, livrando o homem da dependência de coisas materiais. Além disso, o desenvolvimento da trajetória humana resulta de um percurso que perpassa os níveis tecnológico, institucional e cultural (Gonçalves, 1999, p. 128).

Habermas identifica dois campos de ação: o trabalho e a interação social. O primeiro é entendido pelas conquistas do homem sobre a natureza e o segundo diz respeito às normas sociais que regem a convivência dos indivíduos em sociedade, particularmente nas competências de comunicar e agir. Nesse ponto, predomina a ação comunicativa; mais precisamente, uma interação simbolicamente mediada, a qual se orienta "segundo normas de vigência obrigatória que definem as expectativas recíprocas de comportamento e que têm de ser entendidas e reconhecidas, pelo menos, por dois sujeitos agentes" (Gonçalves, 1999, p. 130).

As instituições estão sujeitas à racionalidade instrumental da ciência, afastando-se do plano do argumento e da controvérsia. No outro extremo, a racionalidade instrumental ocupou o lugar da interação comunicativa. As antigas ideologias que regulavam as relações de poder foram suplantadas pela interação comunicativa da comunidade, do ponto de vista das determinações práticas. A racionalidade instrumental não se refere ao certo e ao errado, à justiça ou à injustiça, mas apenas diz se as determinações práticas são ou não adequadas. Por isso, prescindem de valores éticos, políticos ou técnicos (Habermas et al. 1971; Habermas 1990a, 1990b).

Para Habermas (1989), os problemas da sociedade industrial nada ou pouco têm a ver com questões científicas e tecnológicas. As ações dos indivíduos fazem parte de uma rede de interações, de forma que a interação social é uma interação comunicativa.

O campo de ação da racionalidade instrumental esvazia a ação comunicativa, gerando nas pessoas diversas angústias sociais, tais como o isolamento e a competição, somente para citar alguns exemplos. Habermas (1990a, 1994) vislumbra o resgate dessa condição por meio da razão comunicativa, capaz de devolver ao homem seu papel de sujeito.

No campo da saúde, condições mais favoráveis perpassam ações profissionais capazes de conduzir à mudança, no sentido de orientação das práticas e democratização dos acessos. Apenas assim, o bom propósito da "atenção básica" - a saber, o atendimento coletivo e a atenção à saúde - será viável. Então, se capacitada, os esforços de uma equipe multiprofissional de saúde se mostram compatíveis com os conceitos da ação comunicativa, defendida por Habermas (1993), 
à medida que, se educando para a saúde, o aspecto formativo retratará indivíduos mais críticos e participativos, capazes de antecipar-se às expectativas dos pacientes e da comunidade.

\section{Interação}

Uma habilidade importante em Habermas se refere à defesa da verdade, da liberdade e da justiça como parte da estrutura das ações do cotidiano:

As comunicações que os sujeitos estabelecem entre si, mediadas por atos de fala, dizem respeito sempre a três mundos: o mundo objetivo das coisas, o mundo social das normas e instituições e o mundo subjetivo das vivências e dos sentimentos. As relações com esses três mundos estão presentes, ainda que não na mesma medida, em todas as interações sociais (Gonçalves, 2000, p. 120).

A ação interativa se dá a partir da coordenação das ações dos indivíduos envolvidos no processo, de forma que o resultado depende do modo como eles veem o mundo e como atendem aos critérios estabelecidos pelas regras. Observe-se que a interação se dá a partir de normas sociais previamente estabelecidas e aceitas pelos participantes, expressando tais normas as expectativas de todos os elementos do grupo ou as que se desenvolvem no decorrer do processo.

Cada indivíduo, então, espera dos outros elementos determinado comportamento já conhecido pelos demais. A questão não é se uma ação leva ao êxito ou não, mas o quanto os indivíduos a reconhecem e a valorizam, de forma que o não-cumprimento do estabelecido irá gerar coações (Habermas, 1997).

Outro aspecto é que por meio da interação as pessoas retratam experiências, expectativas, desejos, anseios, vivências, objetivos, etc., de tal forma que revelam seu interior. Embora, em alguma medida, isso possa ser controlado pelos seres humanos, em tais situações as pessoas revelam alguma parte de suas convicções e verdades (Habermas, 1993).

É fato que, individualmente, as pessoas pretendem determinadas coisas para as quais buscam validade no processo de comunicação. Tal validade significa corresponder às normas e se adequar a elas, ao mesmo tempo em que as experiências e intimidades das pessoas se deparam com a validade que buscam para suas ações, o que significa que se exige delas sinceridade em suas atuações.

Desse ponto de vista, a linguagem se destaca, à medida em que legitima valores (sinceridade, adequação, atendimento às normas e verdade) nas ações comunicativas, sendo que não pode ser alcançada pela relação meio-fim, mas pelo que está acordado e validado pelo grupo.

A organização social, então, se dá à medida que houver interação dos seres humanos por meio da linguagem e de forma independente de imposições interna e externa. Habermas (1990a) de- 
fende o discurso como parte da capacidade dos indivíduos de se comunicarem, visando à obtenção da legitimidade de suas opiniões e das normas às quais precisam cumprir. A isto denomina agir comunicativo ou interação.

A interação funciona como base do processo de comunicação visando à troca entre os indivíduos, utilizando, para isso, o discurso já legitimado pelas normas e validado em suas proposições. De outra parte, o discurso serve à interação à medida que possibilita aos indivíduos se comunicarem de forma independente e em harmonia (Habermas, 1990c).

A ação comunicativa de Habermas também atende a uma função educacional, por seu caráter interdisciplinar. Diversos autores concordam a respeito disso (Schäfer e Schaller, 1982; Pucci et al., 1994; Freitag e Rouanet, 2005; Freitag, 1994; Flecha, 1996; Peukert, 1996; Prestes, 1996).

\section{DISCUSSÃO}

A Estratégia de Saúde da Família (ESF) tem sua matriz teórica no campo da vigilância à saúde (Merhy; Onoko, 2006), vivendo ainda o desafio de superar a configuração arraigada no modelo médico hegemônico. O modelo que se busca - centrado no usuário -, ao exigir maior capacitação dos profissionais abre caminho para o uso de técnicas de comunicação como uma forma de promover a adesão por parte das equipes espalhadas por todo o Brasil.

As diretrizes do programa preconizam: 1. O caráter substitutivo - proposição de um trabalho centrado na vigilância à saúde, em substituição às práticas convencionais de assistência; 2 . Integralidade e hierarquização - que coloca a Unidade de Saúde da Família no primeiro nível de ações e serviços do sistema local de saúde; 3 . Territorialização e adscrição da clientela por trabalhar com território de abrangência definido; e 4. Equipe multiprofissional - composta por um médico de família, um enfermeiro, um auxiliar de enfermagem e de quatro a seis agentes comunitários de saúde.

Tomando-se por base o conceito de Habermas, uma equipe se organiza em dois momentos distintos: em suas percepções individuais e nos acordos estabelecidos em grupo. As percepções individuais dizem respeito a crenças, vivências, formação, opinião e expectativas, enquanto os acordos estabelecidos perpassam as normas e regras estabelecidas pelo governo e pelas proposições do programa. Em linhas gerais, na execução, tais normas são conhecidas e devem ser cumpridas por todas as equipes.

Uma equipe deve demonstrar objetivos bem definidos, os quais todos os membros se esforcem por alcançar e, nessa direção, a interação dos membros se mostra muito necessária para avaliação do processo, correção e garantia do bem coletivo. O diálogo, então, passa a ser o centro das 
negociações e das trocas, como exercício das capacidades críticas de seus membros, bem como de participação destes, o que se mostra compatível com a ação comunicativa de Habermas.

A equipe também se relaciona a um aspecto de saúde, devendo todos os seus membros se mostrar sadios, e atende ao conceito de receptividade (porta de entrada), visto que é o grupo terciário com o qual os indivíduos mantêm contato, são acolhidos e recebem informações.

Portanto, ações de comunicação se mostram suficientes para estimular a interação comunicativa dos profissionais, buscando a adesão às diretrizes por meio da troca de opiniões, conhecimentos e vivências.

A ação comunicativa permite estabelecer o diálogo na busca pelo autoconhecimento dos indivíduos de um grupo, reconhecer as competências dos demais elementos e estabelecer um acordo sobre as regras fixadas. Na análise deste artigo, os indivíduos são representados pelos profissionais, a equipe é o grupo e as regras são as diretrizes fixadas pelo governo.

Na base da ação comunicativa, é muito importante que entre o grupo haja um comprometimento verdadeiro com as regras estabelecidas. Tal comprometimento deve acontecer no nível da competência pessoal dos profissionais e do conceito de equipe.

Uma abordagem sistêmica deve ter como propostas levantar o conhecimento dos profissionais a respeito de suas próprias funções, das funções dos outros profissionais e do desempenho da equipe para conhecer a opinião dos indivíduos sobre o próprio trabalho e sobre a organização do trabalho em equipe. O principal objetivo dessa abordagem é conhecer, individualmente, as subjetividades do entendimento sobre a tarefa, a interação necessária, o quanto concordam ou não com as diretrizes e o quanto compartilham as mesmas opiniões.

O processo de ação comunicativa deve buscar: 1. A participação de todos os profissionais da equipe; 2. A compreensão deles em relação à orientação para o trabalho; e 3. A percepção, por meio do diálogo, acerca do quanto o desempenho da equipe se mostra em conformidade com os propósitos do governo (regras estabelecidas).

A participação dos profissionais deve ser buscada como instrumento coordenador da ação, tendo em vista que uma condição para a interação é que os integrantes estejam de comum acordo acerca do que consideram como válido para suas expressões e que conheçam intersubjetivamente as pretensões de validade dos demais. Nesse espaço é muito importante garantir a validade das opiniões, para gerar um consenso na conclusão do processo. É nesse momento que ocorrem as negociações e os questionamentos e são identificados outros sentimentos, como contrariedades, incertezas ou anseios. 
Conforme Habermas, a manifestação de validade perpassa três condições: a condição de verdade, a legitimidade e adequação às regras vigentes ou ao estabelecido; e a intenção de quem fala. Esse processo comunicativo é extremamente crítico quanto a validar o que será acordado pelo grupo, considerando o seguinte: a todos os indivíduos é garantida a oportunidade de expressão por meio da comunicação, tomando como base os discursos, os questionamentos e as argumentações.

Um segundo aspecto se refere ao espaço aberto em que a todos os participantes foram oferecidas as mesmas oportunidades de opinar, interpretar, declarar e justificar suas ideias, tendo em vista não desprezar nenhuma ideia a respeito do tema. Nesse espaço permitir-se-á aos participantes a oportunidade de manifestar atitudes, sentimentos e desejos no sentido de manterem-se fiéis aos seus sentimentos e desejos, deixando transparecer seu interior. Por outro lado, assegura-se a possibilidade de os profissionais regularem seus atos, ao agir e influenciar regras e regulamentos: aceitando-as, explicando-as e solicitando-as.

Como base para uma ação comunicativa, a integração dos profissionais deve acontecer voluntariamente, esperando-se que a mobilização da racionalidade seja suficiente para completar a ação dos indivíduos em torno de um entendimento.

Estabelecidas as regras de participação e o consenso, a ação comunicativa consiste em tornar o esforço do grupo em comum acordo para adesão aos objetivos do trabalho.

O objetivo da intervenção por meio da ação comunicativa é oferecer caminhos comuns e articulados para os profissionais viverem experiências que possibilitem aumentar seus conhecimentos acerca de suas próprias atividades e dos demais profissionais, com base em uma visão crítica da realidade e da necessidade de se manterem fiéis às diretrizes (regras). Nesse sentido, a partir da realidade que diz respeito à própria comunidade, os pensamentos e sentimentos (razão subjetiva) orientarão uma participação ativa dentro de princípios de cooperação.

O processo interativo surge da equipe, exigindo o esforço de todos no que se refere a cumprir plenamente a realização de uma ação comunicativa com a pretensão de sua validade. A adesão às diretrizes se concretiza por meio de uma comunicação simétrica e livre. Tal desempenho se revela a partir de um processo comunicativo no qual cada profissional é considerado um ator importante na cena de um diálogo, no momento em que é submetido à interpretação dos outros e também se abre à possibilidade de críticas às suas próprias interpretações.

Assim, a adesão aos objetivos da Unidade Básica de Saúde (UBS) deve ser buscada por meio de um acordo que se desperte no grupo. Os princípios e as normas que guiarão esses profissionais, conforme critérios e redimensionamento do processo de interação, resultarão da interação do grupo, obtida em um consenso. 
A ação comunicativa de Habermas, que tem chamado a atenção de muitas ciências, se mostra como um processo de interação que valoriza o sujeito, a partir de sua individualidade, de como ele vê e percebe o grupo e do quanto se compromete e concorda com as normas após um processo de interação, no qual suas opiniões e atitudes foram compartilhadas, preservadas e vivenciadas.

\section{CONSIDERAÇÕES FINAIS}

Este artigo mostrou que os problemas de promoção da saúde dizem respeito a uma discussão multidisciplinar que pode dar conta da situação. O conceito da ação comunicativa pode ser utilizado nos serviços de saúde, a fim de que atitudes e comportamentos se voltem às práticas criativas e humanizadas, que se refiram à inclusão, respeitando limites e diferenças profissionais.

Em conformidade com a teoria da ação comunicativa, o texto demonstrou que envolver a equipe ativamente na construção de um acordo em torno dos princípios das UBS permite capacitá-la não apenas em torno do desempenho desejado, mas também na interpretação e autoavaliação de suas práticas.

O conceito da ação comunicativa se mostra suficiente para que atitudes e comportamentos se voltem às práticas criativas e humanas. Diante das transformações impactantes que atingem o Sistema Único de Saúde (SUS), uma direção para sua viabilidade social e econômica exigirá da área da saúde uma abordagem multidisciplinar que complemente os seus propósitos.

O futuro da humanidade e os esforços empenhados para solução dos seus problemas passará pela interação que leve a acordos sociais para a produção e o consumo de bens e serviços. A área da saúde está sendo desafiada a manter um modelo no qual o significado se baseie na colaboração de todos os elementos da sociedade envolvidos.

Na busca por um modelo social mais justo, mais responsável e que arrisque menos o futuro das pessoas, o agir comunicativo propõe um significado para as relações dos homens, baseando-se no diálogo, na integração e na cooperação, apontando uma nova direção para profissionais, pacientes e sociedade.

\section{REFERÊNCIAS}

ARAGÃO, Lúcia Maria de Carvalho. Razão comunicativa e teoria social crítica em Jürgen Habermas. Rio de Janeiro: Tempo Brasileiro, 1992. 
BRASIL Política Nacional de Promoção da Saúde. Brasília: Ministério da Saúde / Secretaria de Vigilância em Saúde / Secretaria de Atenção à Saúde, 2006. Disponível em: <http://portal.saude.gov.br/saude>. Acesso em: 25 jun. 2009.

CARVALHO, Denise Maria W. de Competências e atividades: uma contribuição a um estudo da representação. Disssertação (Mestrado em Informática) - PUC-PR, Curitiba, 2003.

DONATO, Ausonia F.; GOMES, Ana Luisa Z. O estudo da comunicação na formação dos profissionais de saúde: algumas questões e aproximações. Bis - Boletim do Instituto de Saúde, São Paulo, v. 12, n. 1, p. 37, abr 2010. Disponível em: <http:// www.isaude.sp.gov.br/smartsitephp/media/isaude/file/bis50-completo.pdf>. Acesso em: 15 maio 2010.

FRANCO, Túlio Batista; MERHY, Emerson Elias. PSF: contradições de um programa destinado à mudança do modelo tecnoassistencial. In: MERHY, Emerson Elias et al. O trabalho em saúde: olhando e experienciando o SUS no cotidiano. São Paulo: Hucitec, 2003.

FREITAG, Barbara. A teoria crítica: ontem e hoje. São Paulo: Brasiliense, 1994.

FREITAG, Barbara; Rouanet, Sérgio Paulo. Dialogando com Jürgen Habermas. Rio de Janeiro: Tempo Brasileiro, 2005.

FREIRE, Paulo. Extensão ou comunicação? São Paulo: Paz e Terra, 2002.

GONÇALVES, Maria A. Salin. Teoria da ação comunicativa de Habermas: possibilidade de uma ação educativa de cunho interdisciplinar na escola. [1999]. Disponível em: <http://www.scielo.br/scielo.php?script=sci_arttext\&pid =S0101-73301999000100007>. Acesso em: 05 abr. 2011.

HABERMAS, Jürgen. Teoría de la acción comunicativa: complementos y estudios previos. 3. ed. Madrid: Cátedra , 1997.

. Técnica e ciência como ideologia. Lisboa. Edições 70, 1994.

Passado como futuro. Rio de Janeiro: Tempo Brasileiro, 1993.

O discurso filosófico da modernidade. Trad. de Ana Maria Bernardo e outros. Lisboa: Publicações Dom Quixote, 1990a.

. Pensamento pós-metafísico: estudos filosóficos. Rio de Janeiro: Tempo Brasileiro, 1990b.

Consciencia moral e agir comunicativo. São Paulo: Brasiliense, 1989.

Dialética e hermenêutica: para a crítica da hermenêutica de Gadamer. Porto Alegre: L\&PM, 1987a.

Conhecimento e interesse. Rio de Janeiro. Guanabara. 1987b.

Teoria de la acción comunicativa II: crítica de la razón funcionalista. Madri: Taurus, 1987c. 
Técnica e ciência como ideologia. Lisboa: Edições 70, 1987d.

HABERMAS, Jürgen et al. Comunicação, opinião pública e poder. In: COHN, Gabriel (Org.). Comunicação e indústria cultural. São Paulo: Cia. Editora Nacional / Edusp, 1971.

IAROZINSKI, Maristela Heidemann. Contribuições da teoria da ação comunicativa de jürgen Habermas para a educação tecnológica. Dissertação (Mestrado em Tecnologia) - Curitiba, Centro Federal de Educação Tecnológica do Paraná, 2000. MERHY, Emerson Elias; ONOKO, Rosana (Org.). Agir em saúde: um desafio para o público. 2. ed. São Paulo: Hucitec, 2006.

PEUKERT, Helmut. Problemas básicos de uma teoria crítica da educação. Educação \& Sociedade, Campinas, Cedes/Papirus, n. 56, p. 412-430, 1996.

PRESTES, Nadja M. Hermann. Educação e racionalidade: conexões e possibilidades de uma razão comunicativa na escola. Porto Alegre: Edipucrs, 1996.

PUCCI, Bruno et al. Teoria crítica e educação: a questão cultural na Escola de Frankfurt. Petrópolis: Vozes, 1994.

RÜDIGER, Francisco. A escola de Frankfurt: Jürgen Habermas. Disponível em: <http://www.robertexto.com/archivo14/ frankfurt_pt.htm>. Acesso em: 05 jan. 2011.

SCHÄFER, Karl Hermann; SCHALLER, Klaus. Ciência educadora crítica e didática comunicativa. Rio de Janeiro: Tempo Brasileiro, 1982.

TEIXEIRA, Ricardo R. Humanização e atenção primária a saúde. Ciências e Saúde Coletiva., Rio de Janeiro, v. 10, n. 3, 2005.

VELASCO ARROYO, Juan Carlos. Para ler Habermas. Madrid: Alianza, 2003.

WITT, Regina R.; ALMEIDA, Maria C. P. O modelo de competências e as mudanças no mundo do trabalho: implicações para a enfermagem na atenção básica no referencial das funções essenciais de saúde pública. Texto \& Contexto - Enfermagem, Florianópolis, v. 12, n. 4, p. 559-68, out.-dez. 2003.

WOLF, Mauro. Teorias das comunicações de massa. São Paulo: Martins Fontes, 2008. p. 271-272.

Recebido em: 4.03.2012 / Aceito em: 31.05.2012 